\title{
FAMILIAR OBJECTS AND MEMORY COLOR
}

\author{
J. Pérez-Carpinell1*, M.D. de Fez ${ }^{1}$, R. Baldoví ${ }^{1}$ and J.C. Soriano ${ }^{2}$ \\ ${ }^{1}$ Depto de Optica. Facultad de Física. Universitat de València. c/ Dr. Moliner, 50. 46100 \\ Burjassot. SPAIN \\ ${ }^{2}$ AIDO. Parc Tecnològic. 46980 Paterna. SPAIN
}

Memory color for a set of eight different familiar objects has been investigated. Our results obtained with one hundred observers, eighty color samples of NCS and two illuminants indicate that: a) the shifts which are produced in the dominant wavelength with memory depend on the familiar object considered; b) colorimetric purity, as a measure of saturation, of the remembered objects is not the same as that of the familiar objects; c) in the SVF representation space, with illuminant D65 and regardless of experience in color matching of the observer the color which was best remembered was purple aubergine and the worst remembered was brown chestnut, with the illuminant A red tomato was the best remembered color and yellow lemon the worst.

Key Words: color vision; memory color; successive color matching; familiar object color

*Correspondence to: Dr. J. Pérez-Carpinell. 


\section{INTRODUCTION}

Simultaneous color matching using a bipartite field is used frequently to measure hue, saturation and brightness in standard colorimetric practice. However, successive color matching is a much more common task than simultaneous matching (more used for technical and scientific work), since in everyday life we rarely compare two colors simultaneously, unless we place them so close together that we can observe them in the same area of the fovea. Therefore, in most cases we compare colors which appear after a certain time lapse, which obliges us to use our memory, since we must match a color which is present with one which is remembered. Reviews can be found where both methods of color matching are studied and compared (Newhall et al. ${ }^{1}$, Hamwi and Landis ${ }^{2}$, Uchikawa ${ }^{3}$, Pérez-Carpinell et al. ${ }^{4}$, etc)

The first studies on color memory were performed almost a century ago $\left(\right.$ Bentley $\left.^{5}\right)$, and since then there have been few specifically related to the discrimination and identification of color using memory; Table I shows some of the best known (Uchikawa ${ }^{6}$ ).

Among the possible research works which are carried out in the field of color memory, we must distinguish between those in which two stimuli appear with a certain time lapse and those in which the memory colors are associated with familiar objects, ie. stimulus tests with an already known form are considered (an apple, an orange etc.), or only verbal information is given, which will be used later to remember the color of a familiar object - memory color.

In the case of familiar objects, ie. those which we see frequently, the term does not coincide with the general definition, in other words, to the ability to remember pure unrelated colors. Bartleson7 states that due to the frequency with which the colors of familiar objects are perceived, their images tend to be relatively stabilised in our memory. Presumably they will not be subject to the same temporal variations associated with the memory of pure colors. The remembered colors are significantly different from the familiar ones since color memory tends to characterise the chromatic features of the object, and in many cases an increase in saturation and luminance can be observed. 
It seems that the less determinant aspects of a color are easily forgotten, as opposed to its more specific character, hue. For example, if we observe a banana, we perceive yellow and black due to its dark streaks. However, when we have to identify the color, we remember it as only yellow, as we have ignored the information regarding black, since according to Newhall et al. ${ }^{1}$... color memory is a selective resultant of the relative impressiveness during perception of the various aspects of stimulation. More dominant, characteristic, and attractive aspects tend to be more impressive, and less dominant aspects tend to be less impressive. The more impressive aspects are more prone to survival in subsequent memory while other aspects are not".

The purpose of the present investigation is the determination of the nature and consistency of color memory associated to eight of these objects, studying: a) Whether our results are affected by the knowledge/experience/ability of the observer in technical and artistic aspects of color, as the bibliography consulted is not conclusive in this respect, ie., while studies such as those of Cohen et al. ${ }^{8}$ and Woods ${ }^{9}$, indicate that these observers have a greater capacity of visual retention, in others no conclusion is reached eg. Burnham and Clark $^{10}$ and Siple and Springer ${ }^{11}$. b) Possible variations with the illuminant; for this experiment, we use a Macbeth cabinet, which has two types of simulator illuminants, A and D65. To check what influence the use of different light sources (similar to those used in everyday life) has on the perception of color. The change of adaptation, on passing from one illuminant to the other, produces a change in appearance of colors (under illuminant A these appear bluer) and usually shows differences of saturation and, for some colors, this effect leads to a change of hue.

The data is analyzed in the SVF representation space ${ }^{12}$, specially adapted to spaces of perception and, considered for the study of color differences a more uniform color space than CIELAB and CIELUV ${ }^{13}$.

\section{METHOD}

$\underline{\text { Stimulus }}$ 
The eight familiar objects we selected were: purple aubergine (PA), green watermelon $(\mathrm{GW})$, green lettuce $(\mathrm{GL})$, yellow lemon $(\mathrm{YL})$, orange $(\mathrm{O})$, pink rose $(\mathrm{P})$, brown chestnut (BC), and red tomato (RT). Chromaticity coordinates for each object in the space CIE 1931(x,y) were determined from the mean of ten values measured at different points of the object, using a telecolorimeter Topcon model BM-7, always considering at least ten of the same objects. These chromaticity coordinates are shown in Table II.

For the study of the memory color of each familiar object we used a grey cardboard rectangular panel, size 42 by $19 \mathrm{~cm}$, and ten comparison color samples, size 37 by $52 \mathrm{~mm}$, see Fig 1 up, chosen from the Natural Color System (NCS) ${ }^{14}$ and distributed around each one of our eight familiar objects (see Fig. 1, down).

The observation took place inside a Macbeth cabinet under two illuminant simulators, D65 and A. The CIE geometry of illumination and viewing for reflection was $0^{\circ} / 45^{\circ}$, and the observation distance of about $40 \mathrm{~cm}$.

The CIE 1931(x,y) coordinates and luminance of the grey rectangular panel were $\mathrm{x}=0.311, \mathrm{y}=0.320$ and $80 \mathrm{~cd} / \mathrm{m} 2$ under the illuminant $\mathrm{D} 65$, and $\mathrm{x}=0.457, \mathrm{y}=0.396$ and 50 $\mathrm{cd} / \mathrm{m} 2$ under the illuminant $\mathrm{A}$.

The Appendix shows, for the two illuminants, D65 and A, the SVF coordinates (Lightness Magnitude $\mathrm{V}_{\mathrm{y}}$ and Opponent-Color Coordinates $\mathrm{F}_{1}$ and $\mathrm{F}_{2}$ ) of the ten comparison samples of each of the eight panels, that correspond to the eight familiar objects studied, accompanied by the notation NCS that identifies them.

\section{Observers}

In order to carry out the different experiments which comprise this study, 100 observers participated, 50 of whom were Physics students (PHY), with no experience in color matching or similar experiments, and the remaining 50 students were from the School of Fine Arts (ARTS), all of whom had wide experience and interest in color. Previously, they were all given the Ishihara test to check that they were normal from a color vision viewpoint.

\section{Procedure}


Before beginning our experiment, we explained to the observers the objective and the experimental method. The observers pre-adapted to laboratory illumination for 5 minutes before each session.

The task of the observers in the experiment was to indicate individually the color of each of the eight familiar objects chosen, using the color information stored in their memories. No additional information was given to observers about the objects to be examined, ie. the description of the objects was deliberately ambiguous and careless, since the aim of the experiment was to determine the nature of common color memory (this obviously resulted in the chromaticities of all these objects varying considerably). With this aim in mind, once the observer was given the name of an object, (s)he examined binocularly the ten comparison color samples distributed on the grey panel and chose the one which best represented the color of a familiar absent object. The necessary time to carry out the experiment was always long enough to ensure complete adaptation to the observation conditions and short enough so that no observer would experience fatigue. Once the observer had completed the series of eight panels (of the eight familiar objects) under one of the Macbeth illuminants, (s)he carried out the same experiment again but this time with the other illuminant. Before starting the experiment with each of the two illuminants, the observer was adapted for 3 minutes to the illuminant looking at a grey panel which was located inside the cabinet. The average time taken in the complete session of the experiment was approximately 15 minutes.

\section{RESULTS}

Table III shows chromaticity coordinates values in CIE 1931(x,y) space and SVF space, for the remembered mean colors by each population (PHY, ARTS) under each illuminant; the values of Chroma (C) and Hue-angle (h) for each group of data appear specified also in the same Table. Figs 2 and 3, with illuminants D65 and A respectively, show the distribution of those same colors in the SVF space with both populations, PHY and ARTS (remembered mean values and correponding standard deviations). 
We should keep in mind that for the part of our experiment that implies a change in the illuminant it is necessary to know the behaviour of NCS samples used as comparison samples. The fact that the observer has to choose unavoidably from a discreet number of samples determines the results, since there is a displacement in the coordinates of the samples and their dispersion also varies. Thus, the standard deviation of the remembered colors will be affected by that dispersion.

As can be seen in the Appendix, most of our comparison samples undergo a decrease in $\mathrm{C}$ and $\mathrm{V}_{\mathrm{y}}$ on changing from illuminant $\mathrm{D}_{65}$ to illuminant $\mathrm{A}$; it is also observed that sample dispersion diminishes, although in different ways according to the color of the familiar object: while for green lettuce, brown chestnut and pink rose sample dispersion remains, for yellow lemon the greatest variation occurs. In this last case, $\mathrm{C}$ diminishes drastically, and the dispersion becomes practically null under illuminant A. Taking into account this behaviour, we expect the standard deviation of the mean remembered colors will be smaller in general for the remembered colors under illuminant $\mathrm{A}$.

\section{ANALYSIS AND DISCUSSION}

\section{1.- Comparative study between familiar object and remembered color}

To find out whether or not our observers have a good color memory, we performed a separate analysis of two of the CIE specifications for the color of an object: dominant wavelength and colorimetric purity, with the aim of observing the changes which appear when we pass from the familiar object to the remembered object. These two magnitudes require a study in the CIE 1931 (x,y) space, as mentioned before, our comparison samples are distributed around the familiar objects used in this experiment.

\section{1.-Dominant wavelength}

Collins15 finds that different wavelengths of the spectrum are not retained equally in the memory and so, while the blue of $460.9 \mathrm{~nm}$ and the yellow of $588 \mathrm{~nm}$ are easily retained 
in the memory, the red of $670 \mathrm{~nm}$ and the green of $535 \mathrm{~nm}$ cause more difficulty. In the same study it is observed that although the blue changes at $486 \mathrm{~nm}$ it continues to be very easy to remember, whereas if green passes from $535 \mathrm{~nm}$ to $500 \mathrm{~nm}$, the color obtained is now much easier to reproduce. The results of Collins' experiment appear to indicate that if a particular green, of $535 \mathrm{~nm}$, or a particular red, of $670 \mathrm{~nm}$, are chosen, they possess some inherent quality which makes it difficult to recognise them again and almost impossible to reproduce them. König and Dieterici ${ }^{16}$ find 3 maximums in the spectrum with reference to the maximum discrimination sensitivity for hue; one of these is $590 \mathrm{~nm}$, very near the 588 $\mathrm{nm}$ of Collins, and this could explain the nature of the results obtained for this wavelength. On the other hand, one of the minimums is found at $540 \mathrm{~nm}$, very near the green $535 \mathrm{~nm}$ of Collins. Hamwi and Landis ${ }^{2}$ indicate in their study that, to Collins' conclusion (corroborated by them) that a change in hue is sufficient to vary the difficulty in reconstruction of a color by memory, it must be added that, the amount of blackness and / or whiteness are involved, and that when an error is made it is more often in the direction of greater blackness rather than less blackness. Nevertheless, authors such as Newhall et al. ${ }^{1}$, Burnham and Clark ${ }^{10}$, Sanders ${ }^{17}$, Bartleson $7,{ }^{18}$ do not find any changes in the dominant wavelength, on carrying out color matching from memory, for fruits, vegetables and other foods.

In Table IV, the dominant wavelengths and the colorimetric purity corresponding to each of the familiar objects used in our experiment and their variation with the illuminants D65 and A are shown. Figs 4 and 5 show with both illuminants, D65 and A respectively, the position in CIE 1931 (x,y) plane, of the familiar objects and the remembered average colors for both populations. From Figs 4 and 5, we can deduce that:

- with both illuminants and regardless of the observer's experience in color matching, the dominant wavelength does not change between the familiar object and the remembered object for yellow lemon.

- with the illuminant of D65, the dominant wavelength does not change either for green water-melon, yellow lemon, pink rose, purple aubergine (in PHY) and red tomato (in ARTS observers). The dominant wavelength increases on passing to the remembered object for orange, red tomato (in PHY observers) and purple aubergine (in ARTS). And finally, decreases for green lettuce and brown chestnut. 
- with the illuminant A, it does not change, in yellow lemon and red tomato (in ARTS). It increases for purple aubergine, orange, pink rose and for red tomato (in PHY). The dominant wavelength decreases for green water-melon, green lettuce and brown chestnut. - from the above information it can be deduced that, in general, as in the works of Siple and Springer ${ }^{11}$ and Bartleson ${ }^{18}$, the relationship between memory hue and familiar hue seems to be unsystematic and specific to the item tested.

\section{2.-Colorimetric Purity}

We have observed in our study (see Table IV) that, as occurs in other studies (Newhall et al. ${ }^{1}$; Bartleson ${ }^{7}$; Burnham and Clark ${ }^{10}$; Siple and Springer ${ }^{11}$; Uchikawa ${ }^{13}$; Collins ${ }^{15}$ ), the purity of the remembered objects is not the same as that of the familiar objects.

From Table IV and Figs 4 and 5 we can conclude that :

- with illuminant D65 colorimetric purity increases for green lettuce, yellow lemon and orange, it does not change for green water-melon, brown chestnut (PHY) and pink rose, and decreases for purple aubergine (ARTS).

- with illuminant A purity increases for green lettuce (PHY), red tomato and purple aubergine, it does not change for yellow lemon, orange, brown chestnut and pink rose, and decreases for green water-melon.

- with illuminant of D65, we have found, in general, that purity increases for familiar objects of high purity (green lettuce, yellow lemon, orange), and it decreases or is unchanged for the familiar objects of midrange and low purity (purple aubergine, green water-melon, pink rose and brown chestnut). Only red tomato, of high purity, remains practically constant.

- with illuminant $A$, the results show a behaviour which increases or decreases the purity of the remembered object similar to that of illuminant $\mathrm{D}_{65}$, except in cases of purple aubergine (low purity of familiar object, increases in the remembered ) and orange (high purity of familiar object, however, the purity of the remembered object remains unchanged). We have not found in the bibliography reviewed any studies performed using illuminant A.

- our results do not indicate in any case that the purity of the remembered object depends on the expertise in color matching of the observer. 


\section{3.- Color difference}

With the purpose of being able to study how the different familiar objects have been remembered we use to the originated color difference, that is why we need to move to uniform space in order to establish a metric. For that reason we use the SVF color representation space that presents greater uniformity for the study of color differences than those adapted in 1976 by the CIE (CIELAB and CIELUV). Thus we can compare the color of the familiar objects and remembered ones by the observers. We have calculated the variation of the lightness magnitude, $\mathbf{V}_{\mathbf{y}}$, Chroma, $\mathbf{C}\left(\mathrm{C}=\sqrt{\mathrm{F}_{1}^{2}+\mathrm{F}_{2}^{2}}, \Delta \mathrm{C}=\mathrm{C}_{2}-\mathrm{C}_{1}\right)$ and hueangle $\mathbf{h}\left(\mathrm{h}=\tan ^{-1} \mathrm{~F}_{2} / \mathrm{F}_{1}, \Delta \mathrm{h}=\mathrm{h}_{2}-\mathrm{h}_{1}\right)$, as well as the color difference, $\Delta \mathbf{E}$, in the SVF space $\left(\Delta \mathrm{E}=\sqrt{\left(2.3 \Delta \mathrm{V}_{\mathrm{y}}\right)^{2}+\left(\Delta \mathrm{F}_{1}\right)^{2}+\left(\Delta \mathrm{F}_{2}\right)^{2}}\right.$ ) between the remembered colors and the familiar colors. These data, for PHY and ARTS populations respectively, are shown in Tables V and VI; in Figs 6 and 7 we represent the SVF color difference, $\Delta \mathrm{E}$ between the mean color sample selected by PHY/ARTS populations and D65/A illuminants respectively.

To be able to compare the results corresponding to the different colors, we normalize our results. For this purpose we divide the color difference $\Delta \mathrm{E}$ obtained by the smallest color difference that the observers could select, that is to say, the distance that exists between the familiar objects and the nearest NCS sample. Thus we have information on the ratio between the remembered color and the reference one. These values appear in the last column, $\Delta \mathrm{En}$, of Tables $\mathrm{V}$ and VI, and show that the closer the value is to unit, the better remembered the color of the familiar object. The Tables also show that the observers choices are distributed very close to this mean remembered color, and not along the group of the 10 comparison samples.

Thus we deduce that:

The best remembered colors with illuminant $\mathrm{D}_{65}$ are purple aubergine $(\Delta \mathrm{E}=1.31)$ and green lettuce (1.33) for PHY, and purple aubergine (1.25) and green water-melon (1.26) for ARTS. With illuminant $\mathrm{A}$ are red tomato $(\Delta \mathrm{E}=1.34)$, purple aubergine (1.35) and green water-melon (1.36) for PHY; green water-melon (1.31) and red tomato (1.34) for ARTS. 
The worst remembered colors with illuminant D65 and for both populations are brown chestnut $(\Delta \mathrm{E}=3.81$ for PHY, 4.40 for ARTS $)$ and orange $(\Delta \mathrm{E}=2.39$ for PHY, 2.30 for ARTS). With illuminant A they are yellow lemon ( $\Delta \mathrm{E}=2.47$ for PHY, 2.24 for ARTS) and pink rose $(\Delta \mathrm{E}=2.06$ for PHY, 2.10 for ARTS $)$.

\section{$\underline{\text { 2.-Comparative study between populations }}$}

We have calculated the mean SVF $\Delta \mathrm{V}_{\mathrm{y}}, \Delta \mathrm{C}$ and $\Delta \mathrm{h}$, as well as the total color difference, $\Delta \mathrm{E}$, from the mean remembered colors by the populations of PHY and ARTS under our two illuminants. These data are shown in Tables VIII. From the study of the Tables VIII-a) and VIII-b), and of the Fig 6, where we only represent $\Delta \mathrm{E}$ (between the mean remembered color selected by the populations of PHY and ARTS) for both illuminants, we can deduce the changes related to the behaviour of the memory of color of our familiar objects keeping in mind the factor 'experience / inexperience' in color of the observer.

\section{1-Influence of 'experience/inexperience' in color of the observer.}

We should be noted that in this section this influence will play an important role in the change in the dispersion of the comparison samples, since if these have smaller dispersion for a natural object with one of the illuminants, the remembered colors by both populations will be closer than with the other illuminant which can lead to erroneous interpretations.

a) Illuminant D65: of the analysis of the Table VIII-a) it is deduced that the remembered colors showing a greater difference between the populations, PHY and ARTS, are: red tomato $(\Delta \mathrm{E}=1.65)$, pink rose $(0.99)$, purple aubergine $(0.88)$ and brown chestnut (0.85). The remembered colors with a greater similarity are green water-melon $(0.30)$ and green lettuce (0.34).

Statistically, from the t-student analysis applied to our results and comparison of the color differences between both populations (see Table VII), we cannot affirm that these colors are remembered in a different way by both populations, experienced/inexperienced 
observers in color, with the exception of the brown chestnut, which is in the limit of the confidence interval of the analysis $(\alpha=0.05)$.

The most important contribution to the color difference is due to the chroma, that is always smaller for the population of ARTS. The fact that the population of PHY adds more chroma to the memorized color could perhaps indicate that the students of ARTS are more accurate in the chroma matching of a color, are more accustomed to reproducing its chroma or have assumed that to reproduce a color they have respect the original chroma.

Changes in hue angle are generally negligible, only red tomato, brown chestnut and purple aubergine overcome $3^{\circ}$ of difference between both populations (purple aubergine has a decrease of almost $6^{\circ}$ ); they are colors where the 10 samples present a big dispersion in hue, but are not the only ones. The tendency is toward a greater difference in hue for those familiar objects that present greater dispersion in hue.

Contribution of Lightness Magnitude $\mathrm{V}_{\mathrm{y}}$ is negligible compared with Chroma $\mathrm{C}$, it would only be necessary to emphasise the high values for pink rose and red tomato, which are however always below $\Delta \mathrm{C}$. In both cases the population of ARTS remembers the color with the greatest $\mathrm{V}_{\mathrm{y}}$ value. It should be noted that with these two colors the observers had comparison samples with a wide range of values both in $\mathrm{C}$ as in $\mathrm{V}_{\mathrm{y}}$, so that the dispersed election of the samples makes the contributions of $\mathrm{C}$ and $\mathrm{V}_{\mathrm{y}}$ similar. This is also the case for green water-melon but now the most part of the observers have chosen only one sample, and for this reason there is a minimum color difference between populations and both contributions are very small.

b) Illuminant A: from analysis of Table VIII-b) we conclude that the remembered colors with a greater difference for both populations are: red tomato $(\Delta \mathrm{E}=1.16)$ and brown chestnut $(\Delta \mathrm{E}=1.00)$. The remembered colors with more similarity are yellow lemon $(\Delta \mathrm{E}=0.06)$ and green water-melon $(\Delta \mathrm{E}=0.17)$, with much smaller differences in color that the outcomes with illuminant D65. In both cases the dispersion of the samples has diminished, mainly for yellow lemon where it has become practically null. For this color and under this illuminant, the coordinates of the 10 comparison samples are practically identical, the election of any one of the ten samples leads to a near color difference of zero, and therefore the observers have not always selected the same sample, but rather they have 
distributed the selection frequencies along the 10 available samples. Analysis of Table VII does not provide sufficient statistical evidence to state that colors are different, excepting brown chestnut $(\alpha=0.01)$.

Once again the chroma contribution is the most important, and again it is smaller for the population of ARTS with most of the colors. The maximum value is obtained with purple aubergine $(\Delta \mathrm{C}=0.32)$, and for yellow lemon $(\Delta \mathrm{C}=0.04)$ there are almost no differences.

In reference to the hue angle we can observe negligible variations, the most important being red tomato, but always with values smaller than $2.5^{\circ}$. Although under illuminant $A$ the 10 comparison samples of the panel present variations in hue somewhat smaller or similar to those of illuminant D65, there is no relation between the hue dispersion and hue variations obtained, $\Delta \mathrm{h}$.

The contribution of $\mathrm{V}_{\mathrm{y}}$ has a similar behaviour to that under illuminant $\mathrm{D}_{65}$, this is to say, they are much smaller than the changes in chroma and they do not have a prominent contribution, in general, to color difference $\Delta \mathrm{E}$. The greatest differences between populations are for brown chestnut $\left(\Delta \mathrm{V}_{\mathrm{y}}=-0.28\right)$ and red tomato $(0.26)$.

In general color differences are smaller with illuminant A, except for green lettuce and brown chestnut. For these colors the dispersion of the samples practically stays constant, for this reason an increase in the color difference really does represent a significant change in behaviour.

As the 10 comparison samples of each familiar object are not distributed regularly in the SVF space, we will normalize the color differences $\Delta \mathrm{E}$ dividing each one of these by the greatest distance that exists between the two comparison samples which are farthest apart and thus we obtain the normalized color difference, $\Delta \mathrm{En}$ (see last column in TableVIII). This provides information on the observers' choices, since it indicates if the distance between remembered colors is great or not, compared with the maxim that they could have chosen. We can see that:

-with illuminant D65 (see Table VIII-a): the remembered colors by both populations with greater similarity way $(\Delta \mathrm{En}$ minimum) are green water-melon $(\Delta \mathrm{En}=0.031)$ and green 
lettuce $(0.035)$, while those remembered with greater difference way ( $\Delta$ En maximum) are red tomato $(0.233)$ and brown chestnut $(0.113)$.

- with illuminant A (see Table VIII-b): the remembered colors with greater difference way are again red tomato $(0.173)$ and brown chestnut $(0.144)$, and those remembered with greater similarity way are green water-melon (0.021), purple aubergine (0.048) and pink rose (0.050). Yellow lemon (0.098) is an intermediate color, due to the fact that the observers have not always chosen the same sample.

As already mentioned, our statistical analysis of both illuminants (see Table VII), shows again that only brown chestnut is remembered differently for both populations.

\section{2-Influence of illuminant.}

We have also obtained the mean SVF $\Delta \mathrm{V}_{\mathrm{y}}, \Delta \mathrm{C}, \Delta \mathrm{h}$ and $\Delta \mathrm{E}$ of the remembered colors, for each of the populations, when changing illuminant D65 to iluminant A. These data appears in Tables VIII-c), for PHYS students, and VIII-d), for ARTS students. From the study of these Tables and Fig 7, which show the SVF color differences $\Delta \mathrm{E}$ (between the remembered mean colors when changing illuminant) for each population, PHY and ARTS, respectively, we can deduce the behaviour of color memory of our familiar objects taking the illuminant as variable. It is observed that $\Delta \mathrm{E}$ have increased considerably due to displacement of both the familiar objects and the comparison samples. We cannot establish a clear difference between the contributions of $\mathrm{V}_{\mathrm{y}}$ and $\mathrm{C}$. Moreover, $\Delta \mathrm{h}$ takes values among $4^{\mathrm{o}}$ for purple aubergine and $26^{\circ}$ for yellow lemon.

The most noticiable behaviour of $\Delta \mathrm{E}$ when changing illuminant is given for yellow lemon, with values greater than 14 units for both populations, due to the fact that the chromaticity coordinates of the 10 samples have moved now to another region of the representation space with an appreciable decrease in $\mathrm{C}$. The rest of the colors present values of $\Delta \mathrm{E}$ less than 7 units, and the colors which have the smallest variations are purple aubergine $(\Delta \mathrm{E}=2.53$ for PHY and 2.63 for ARTS $)$, brown chestnut and green water-melon, with values of $\Delta \mathrm{E}$ always below 4 units.

With the change of illuminant, the PHY population only remembers in a similar way (the data do not provide sufficient statistical evidence to state that the colors compared are 
different, since $\alpha>0.05)$ purple aubergine $(\alpha=0.61)$, green lettuce $(\alpha=0.29)$ and pink rose $(\alpha=0.58)$; for ARTS population, with the change of illuminant, the colors remembered in a similar way are brown chestnut $(\alpha=0.20)$ and again pink rose $(\alpha=0.13)$.

\section{CONCLUSIONS}

1.- With familiar objects, mean chromaticity coordinates CIE $(\mathrm{x}, \mathrm{y})$ and SVF coordinates $\left(\mathrm{V}_{\mathrm{y}}, \mathrm{F}_{1}, \mathrm{~F}_{2}\right)$ of the familiar objects are different from those obtained for memory.

2.- We have verified that the shifts produced in the dominant wavelength with memory depend on the familiar object considered (see Figs 4 and 5).

3.- Colorimetric purity of familiar objects is not the same as that of remembered objects. With illuminant D65, purity of the remembered objects increases for familiar objects with high purity values and decreases or remains unchanged for familiar objects of midrange and low purities. Colorimetric purity of the remembered object is, in general, regardless of experience in color matching of the observer. (see Table IV).

4.- With illuminant D65 and regardless of experience in color matching of the observer, the color which is best remembered is purple aubergine and the one which is worst remembered is brown chestnut (see Tables V-a) and VI-a).

5.- With illuminant A, red tomato, purple aubergine and green water-melon are the best remembered colors for PHY, green water-melon and red tomato for ARTS, and yellow lemon and pink rose are the worst remembered colors for both populations (see Tables V-b) and VI-b).

6.- With both illuminants, green water-melon is remembered the same, and brown chestnut $(\alpha<0.05)$ is the object that is remembered in the most different way by the experienced / inexperienced in color observer. 
7.- With the change of illuminant the behaviour of both populations is different. Table VII shows that: whereas purple aubergine $(\alpha=0.61)$ and green lettuce $(\alpha=0.29)$ are remembered in a similar way for PHY population but in a different way for ARTS population $(\alpha=0.01$ for both colors), brown chestnut is remembered in a different way for PHY population $(\alpha<0.01)$ and in a similar way for ARTS population $(\alpha=0.20)$.

\section{ACKNOWLEDGEMENTS}

This research was supported in part by a grant from ADEIT- Universitat de València and IMPIVA to M.D. de F. 


\section{REFERENCES}

1. S.M. Newhall, R.W. Burnham and J.R.Clark, Comparison of successive with simultaneous color matching. J. Opt. Soc. Am. 47, 43-56 (1957).

2. V. Hamwi and C. Landis, Memory for color. J. Psychol. 39, 183-194 (1955).

3. K. Uchikawa, Purity discrimination: successive vs simultaneous comparison method. Vision Res. 23, 53-58 (1983).

4. J. Pérez-Carpinell, R. Baldoví, M.D. de Fez and J. Castro, Color memory matching: time effect and other factors. Color Res. Appl. 23(4), 00-00 (1998).

5. I.M. Bentley, The memory image and its qualitative fidelity. J. Psychol. 11, 1-48 (1899).

6. K. Uchikawa, Categorical color perception and color memory. Invited lecture at AIDO color vision course. AIDO. Valencia. Spain (1993).

7. C.J. Bartleson, Memory colors of familiar objects. J. Opt. Soc. Amer. 50, 73-77 (1960).

8. J.S. Cohen, L. Welch and V.R. Fisichelly, An objective test of visual retention capacity. J. Psychol. 32, 43-47 (1951).

9. W.A. Woods, The Color Aptitute Test. Color Division, Industrial Psychology Laboratory. Sparta, N.J. (Box 318). (1952).

10. R. W. Burnham, and J.K. Clark, A test of hue memory. J. Appl. Psychol. 39, 164-172 (1955).

11. P. Siple, and R.M. Springer, Memory and preference for the colors of objects. Percept. Psychophys. 34, 363-370 (1983).

12. T. Seim, and A. Valbereg, Towards a uniform color space: a better formula to describe the Munsell and OSA color scales. Color Res. Appl. 11, 11-24 (1986).

13. M. Mahy, L. Van Eycken and A. Oosterlinck, Evaluation of uniform color spaces developed after the adoption of CIELAB and CIELUV. Color Res. Appl. 19, 105-121 (1994).

14. Natural Color System (NCS). Skandinaviska Farginstitutet AB. Stockholm. Sweden (1980).

15. M. Collins, Some observations on immediate colour memory. Brit. J. Psychol. 22, 344352 (1931-1932). 
16. A. König, and C. Dieterici, Ueber die empfindlichkeit des normalen auger für wellenlängenunterschiede des lichtes. Ann. Phys. Chem, 22, 579-589 (1884).

17. C.L. Sanders, Color preferences for natural objects. Illum. Engin. 54, 452-456 (1959).

18. C.J. Bartleson, Color in memory in relation to photographic reproduction. Photo. Sci. Engin. 3, 114-117 (1961). 


\section{FIGURE LEGENDS}

FIG. 1 a) Arrangement of the comparison color samples on the grey panel. b) 1931 CIE $(\mathrm{x}, \mathrm{y})$ chromaticity diagram, showing position of the reference tests $(\mathrm{x})$ and comparison samples under illuminant $\mathrm{D}_{65}$.

FIG. 2 Chromaticity coordinates in the $\operatorname{SVF}\left(\mathrm{F}_{1}, \mathrm{~F}_{2}\right)$ plane (up), and SVF $(\mathrm{C}, \mathrm{V})$ plane (down), showing the position of the familiar objects (crosses) and the remembered average colors \pm SD (filled for PHY students and open for ARTS students). Illuminant $\mathrm{D}_{65}$.

FIG. 3 As Fig. 2 but for illuminant A.

FIG. 4 Position, in CIE 1931 (x,y) plane, of the eight familiar objects (crosses) and the remembered average colors (filled for PHY students and open for ARTS students). Illuminant $\mathrm{D}_{65}$.

FIG. 5 As Fig. 4 but for illuminant A.

FIG. 6 Variations, for the eight familiar objects, of SVF color difference between the mean color sample selected by PHY students / ARTS students. $\square$ Illuminant $\mathrm{D}_{65}$; illuminant A.

FIG. 7 Variations, for the eight familiar objects, of SVF color difference between the mean color sample selected with illuminant $\mathrm{D}_{65}$ / illuminant A. $\square$ PHY students; $\square$ ARTS students. 
a)

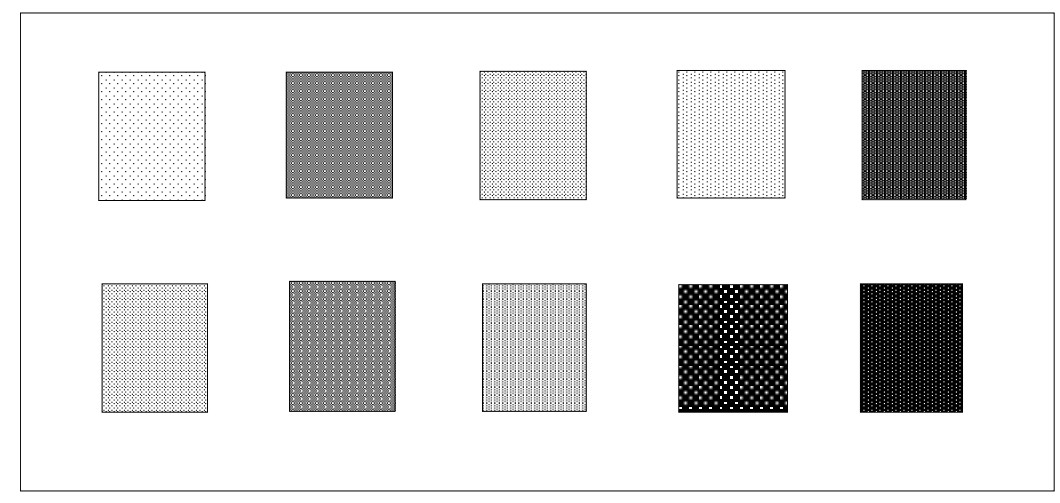

b)

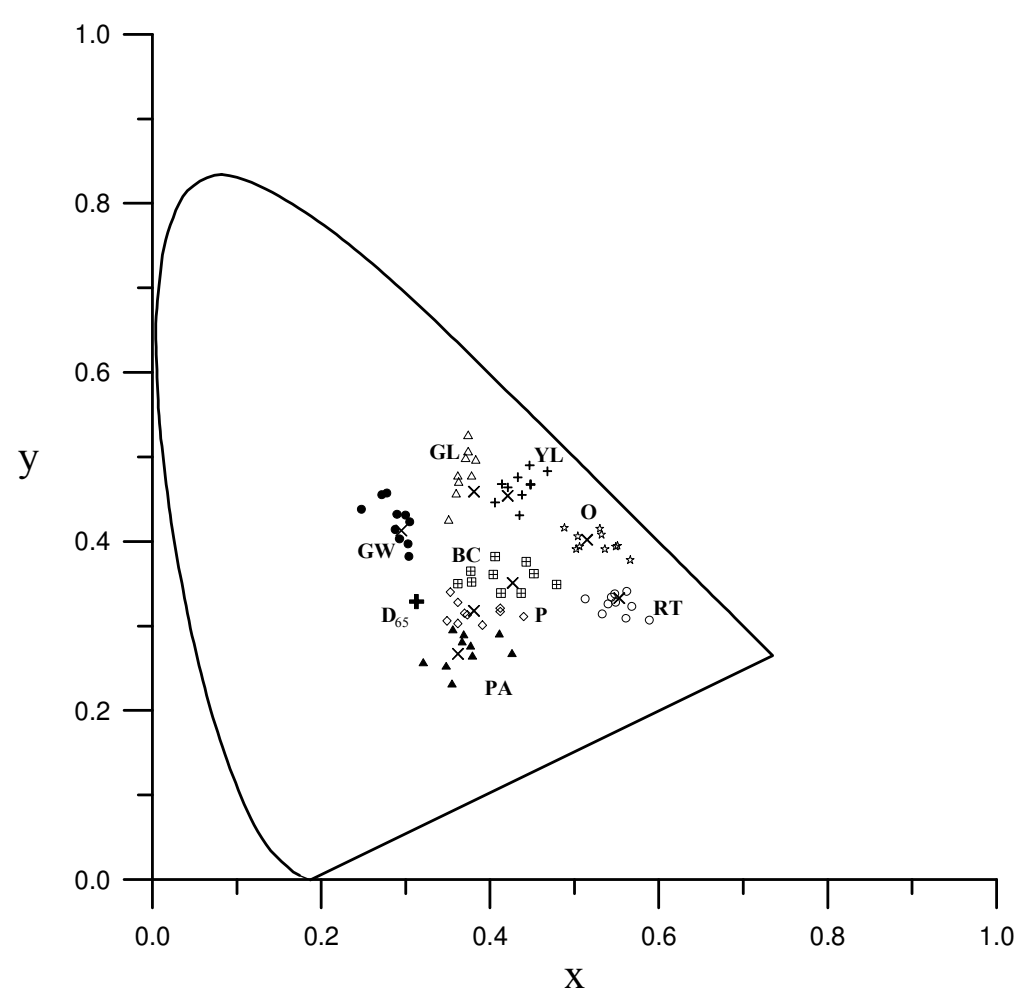



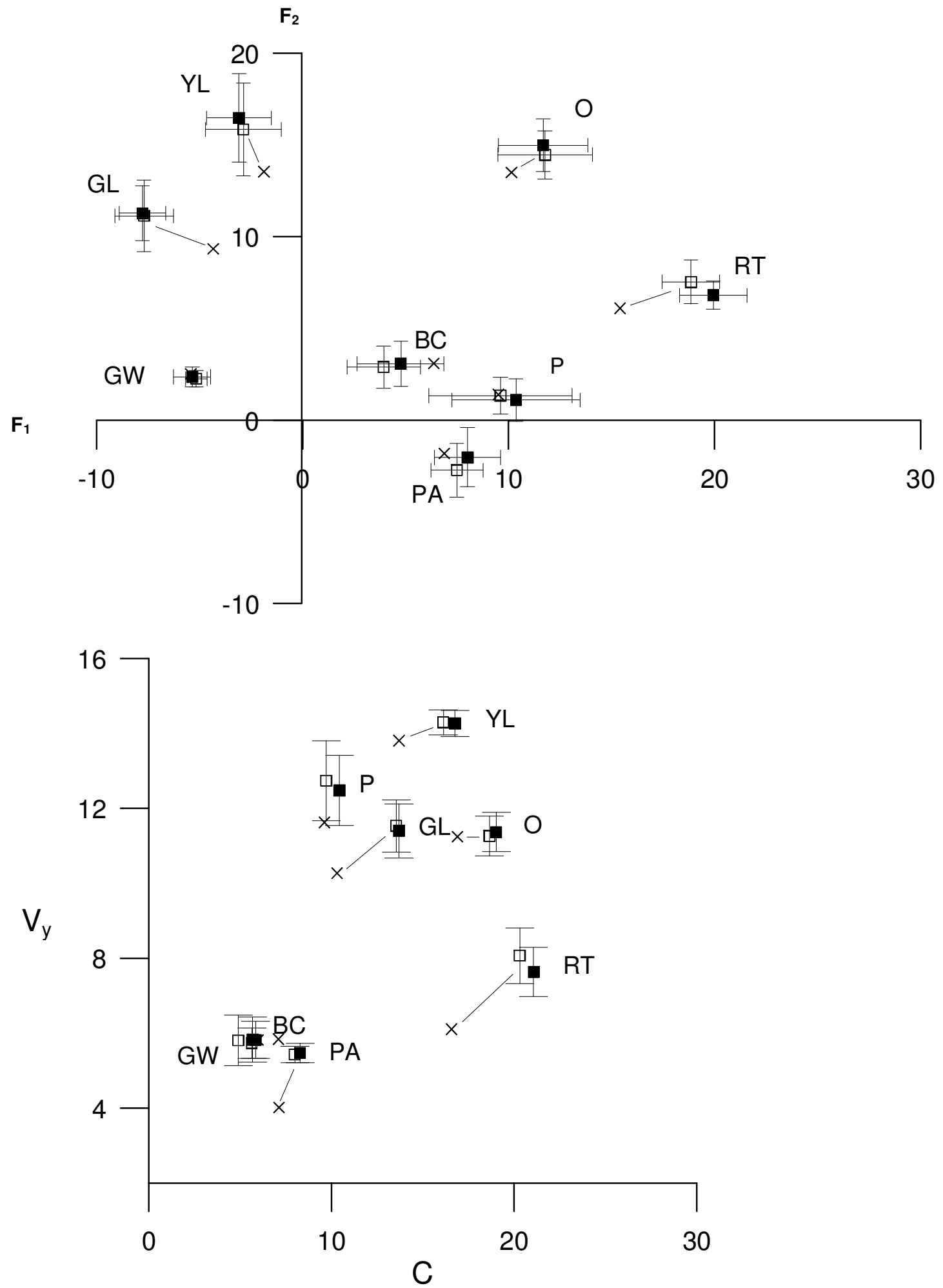

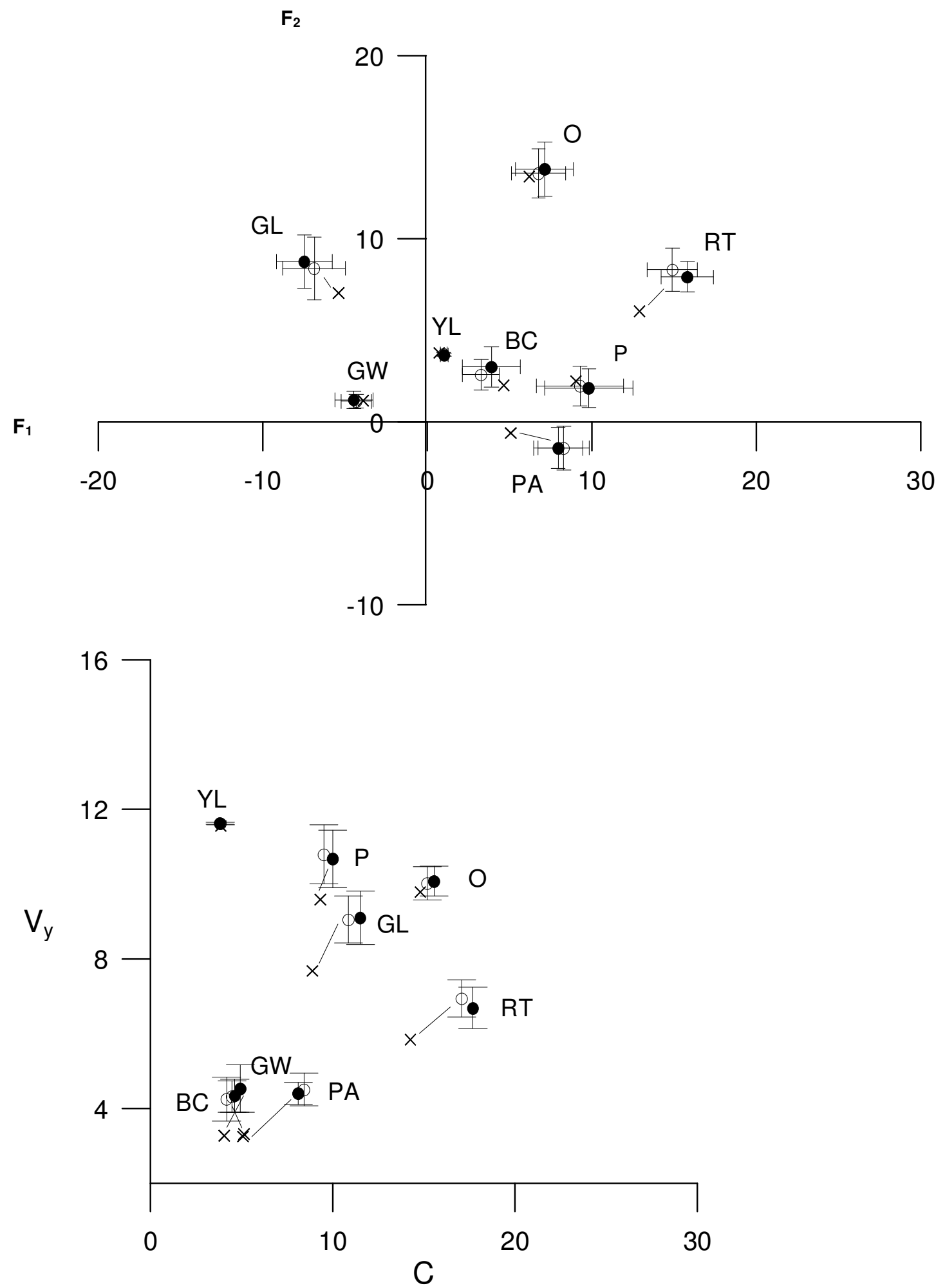


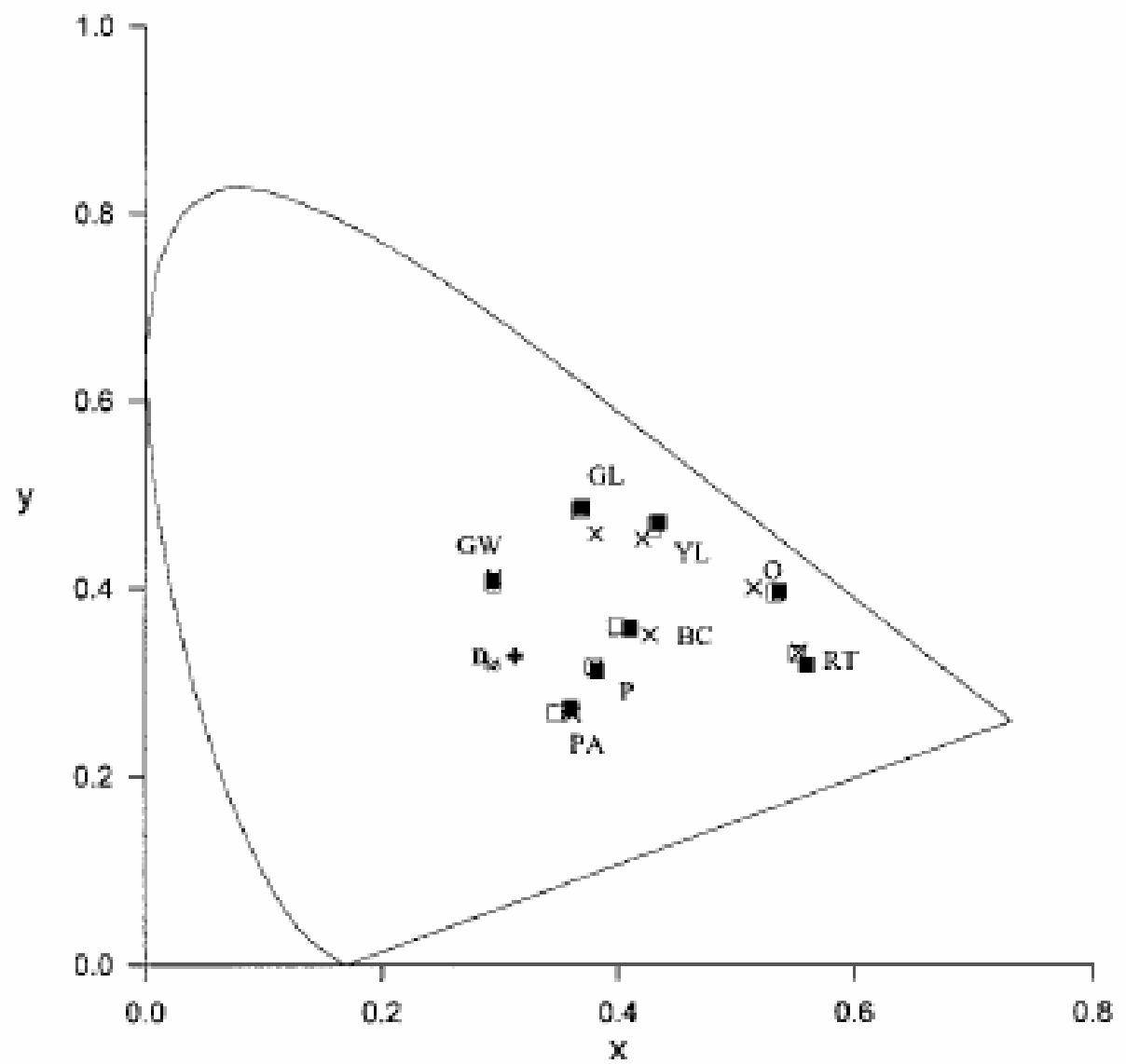




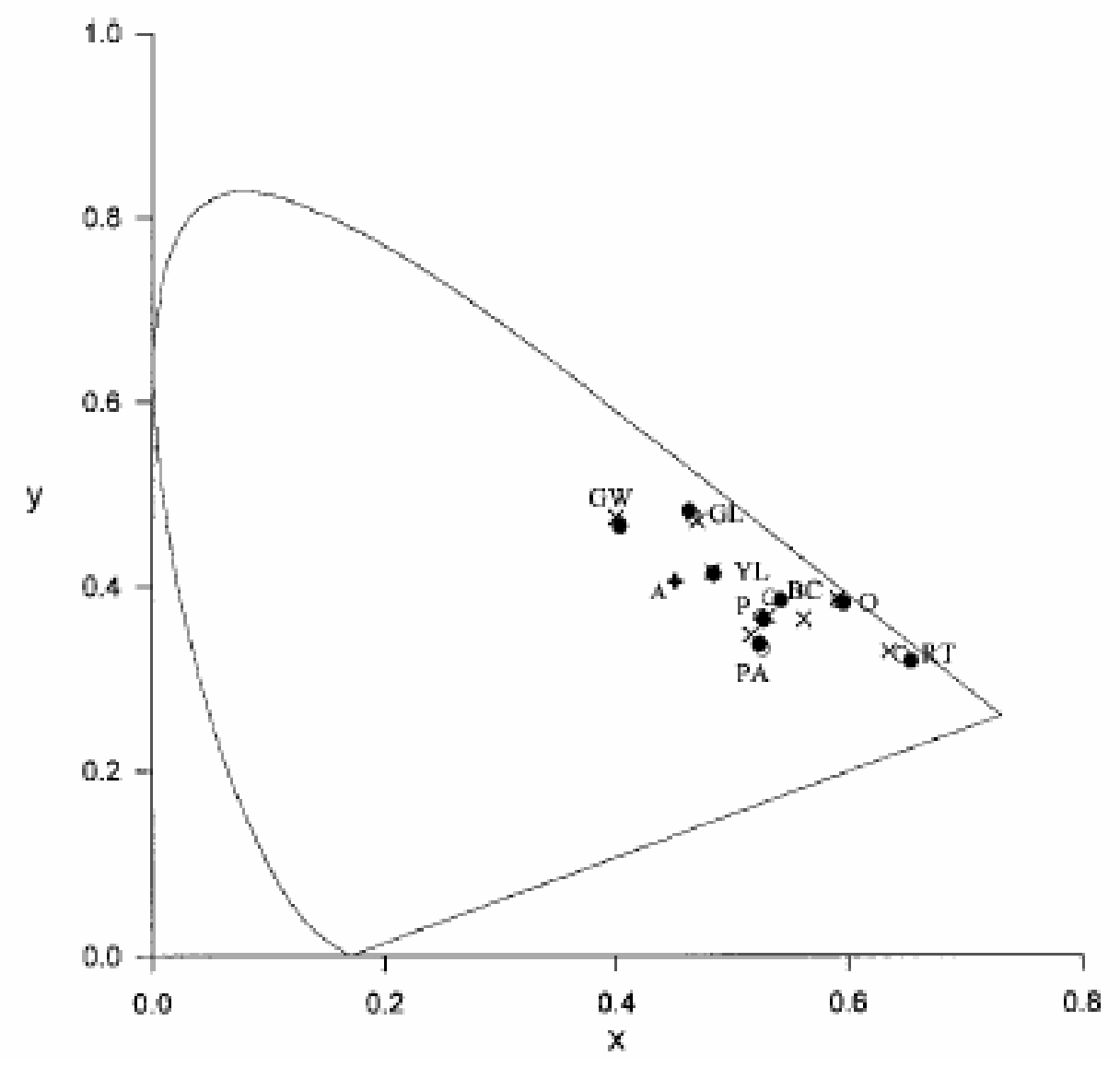




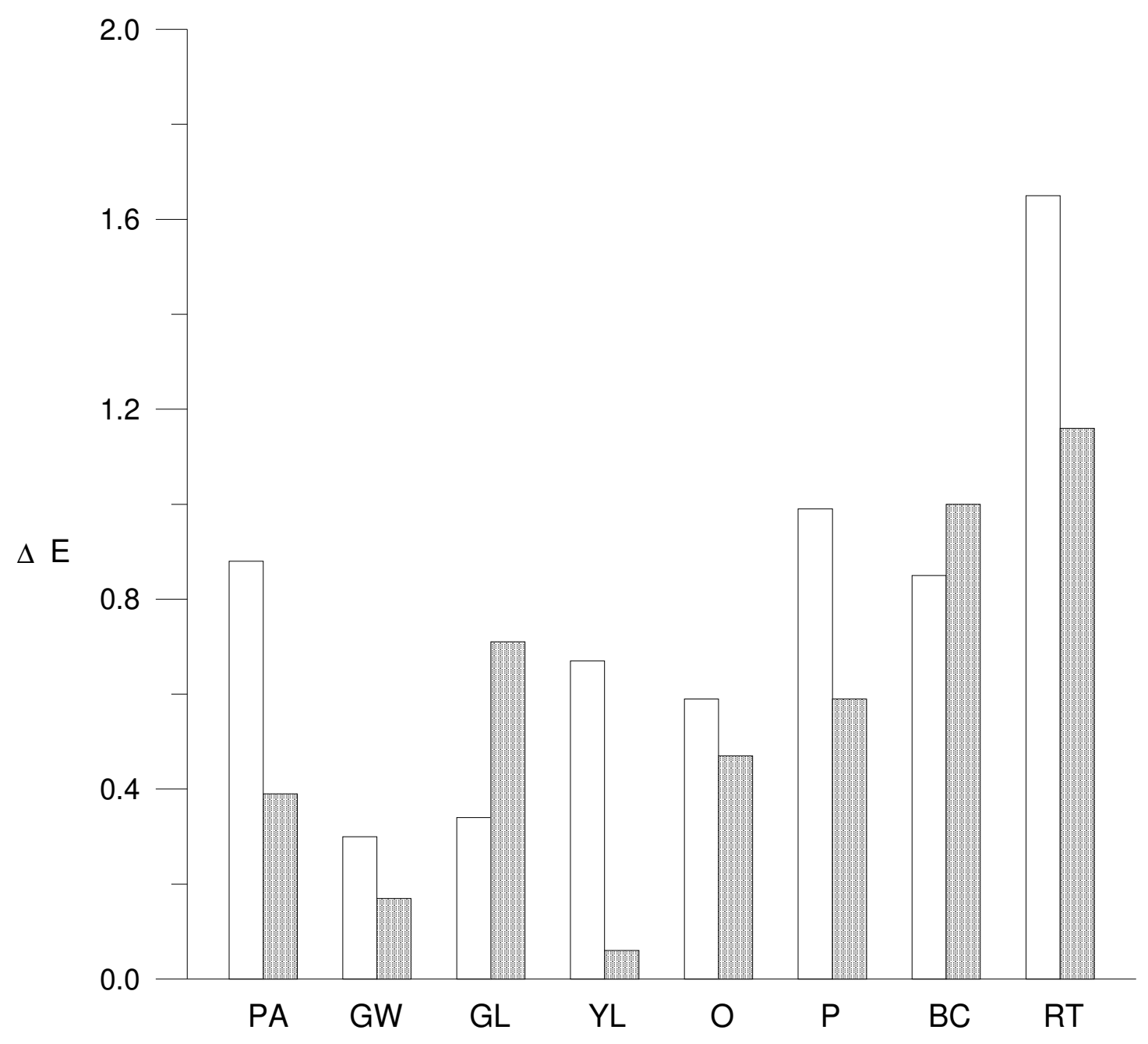




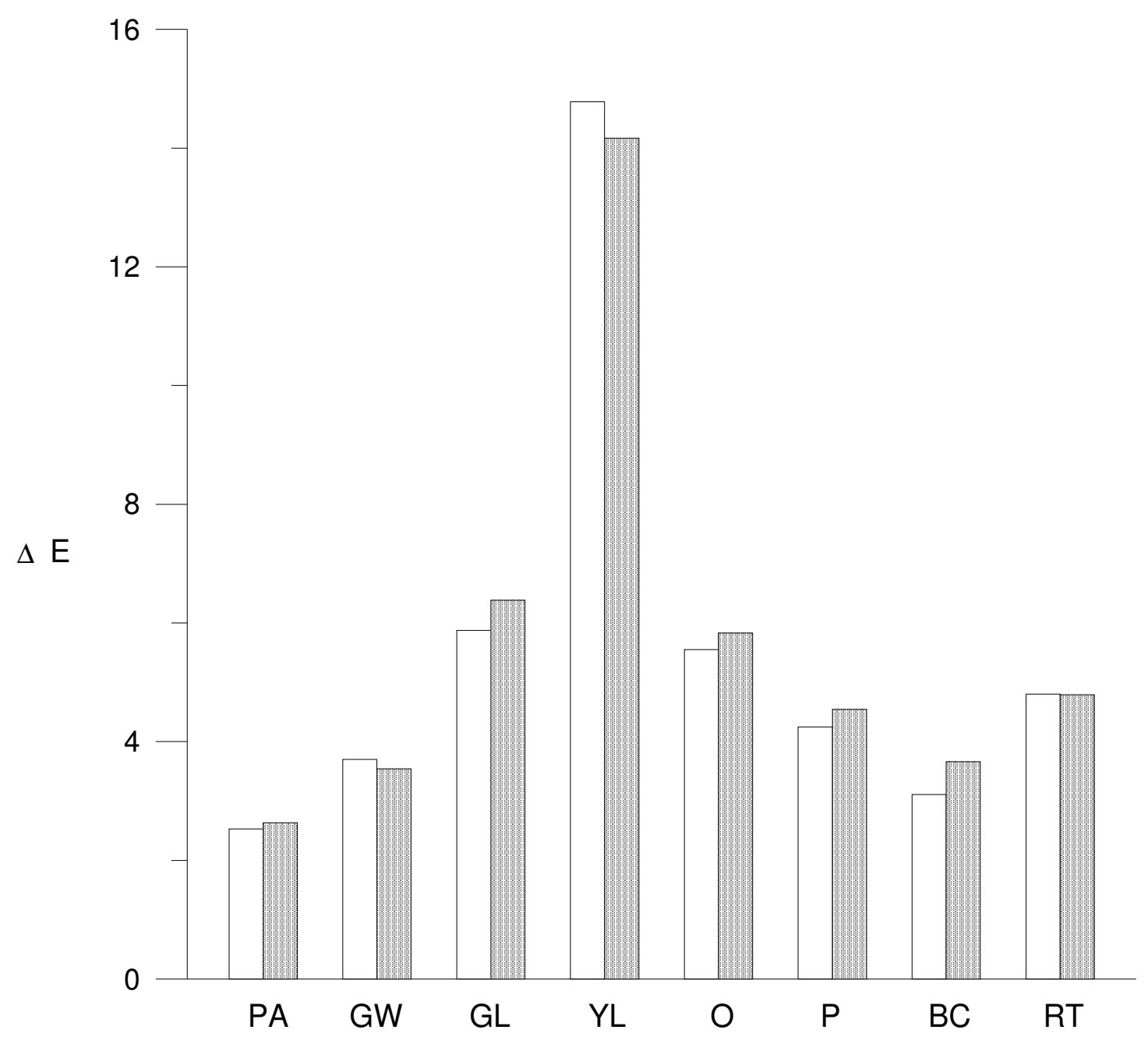




\section{CAPTIONS FOR TABLES}

Table I: Some previous studies on color memory (Uchikawa, 1993).

Table II: 1931 CIE $(\mathrm{x}, \mathrm{y})$ chromaticity coordinates and luminances of eight familiar objects used in the experiment. a) illuminant $\mathrm{D}_{65} ;$ b) illuminant $\mathrm{A}$..

Table III: 1931 CIE $(\mathrm{x}, \mathrm{y})$ chromaticity coordinates, $\mathrm{SVF}$ coordinates $\left(\mathrm{V}_{\mathrm{y}}, \mathrm{F}_{1}, \mathrm{~F}_{2}\right)$, Chroma C and hue $\mathrm{h}$, for the remembered average color, for PHY students and ARTS students, repectively. a) Illuminant $D_{65}$; b) illuminant $A$.

Table IV: Dominant wavelengths and colorimetric purity of each of the familiar objects with both illuminants; colorimetric purities of the remembered colors por both populations and illuminants.

Table V: Variation of mean SVF lightness difference, $\Delta \mathbf{V}_{\mathbf{y}}, \mathrm{SVF}$ chroma difference, $\Delta \mathbf{C}$, SVF hue difference, $\Delta \mathbf{h}$, SVF color difference, $\Delta \mathbf{E}$ and normalized SVF color difference, $\Delta$ En. PHY population. a) Illuminant $\mathrm{D}_{65}$; b) illuminant $\mathrm{A}$.

Table VI: As Table V but for ARTS population. a) Illuminant $\mathrm{D}_{65} ;$ b) illuminant $\mathrm{A}$.

Table VII: Relation of t-statistic values and significant coefficients for both populations. PHY and ARTS students, and illuminants $\mathrm{D}_{65}$ and $\mathrm{A}$.

Table VIII: a) Mean SVF lightness difference $\Delta \mathbf{V}_{\mathbf{y}}$, SVF chroma difference, $\Delta \mathbf{C}$, SVF hue difference, $\Delta \mathbf{h}, \mathrm{SVF}$ color difference, $\Delta \mathbf{E}$ and normalized SVF color difference, $\Delta \mathbf{E n}$ for the PHY students-ARTS students relation. Illuminant $\mathrm{D}_{65} ; \mathbf{b}$ ) as a) but for illuminant $\mathrm{A}$; c) Mean SVF lightness difference $\Delta \mathbf{V}_{\mathbf{y}}$, SVF chroma difference, $\Delta \mathbf{C}$, SVF hue difference, $\Delta \mathbf{h}$, and SVF color difference, $\Delta \mathbf{E}$, for illuminant $\mathrm{D}_{65}$-illuminant $\mathrm{A}$ relation. PHY studens; $\mathbf{d}$ ) as c) but for ARTS students. 
Table I: Some previous studies on color memory (Uchikawa, 1993).

\section{Authors}

- Collins (1931-32)

- Hanawalt y Post (1942)

- Hamwi y Landis (1955)

- Burnham y Clark $(1954,1955)$

- Newhall et al. (1957)

- Heider y Oliver (1972)

- Bartleson (1960)

- Uchikawa e Ikeda (1981)

- Nilsson y Nelson (1981)

- Uchikawa (1983)

\section{Method}

- Monochromatic lights, matching

- Color papers, matching

- 10 Ostwald color chips, selecting

- 20 Munsell hue chips, selecting

- 25 Munsell color chips, matching

- 40 Munsell color chips, selecting

- Familiar objects, selecting

- 22 monochromatic lights, same or different judgment

- 16 monochromatic lights, matching

- 5 purities of 7 dominant

wavelengths, same or different

judgment

- Siple y Springer (1983)

- Familiar objects, matching

- Allen (1984, 1990)

- Uchikawa e Ikeda (1986)

- Romero et al. (1986)

- Boynton et al. (1989)

- Uchikawa y Shinoda (1990)
- 12 color cards, selecting

- 10 luminances of 6 monochromatic and a white lights, matching

- 4 colored lights, same or different

- OSA color chips, same or

different judgment

- CRT colors, same or different judgment, selecting. 
Table II: $1931 \mathrm{CIE}(\mathrm{x}, \mathrm{y})$ chromaticity coordinates and luminances of eight familiar objects used in the experiment. a) illuminant $D_{65}$; b) illuminant $A$.

\begin{tabular}{|l|c|c|c|}
\cline { 2 - 4 } \multicolumn{1}{c|}{} & $\mathbf{x}$ & $\mathbf{y}$ & $\mathbf{Y}\left(\mathrm{cd} / \mathrm{m}^{2}\right)$ \\
\hline Purple aubergine & 0.362 & 0.267 & 12.4 \\
\hline Green water-melon & 0.295 & 0.413 & 27.8 \\
\hline Green lettuce & 0.381 & 0.459 & 110.0 \\
\hline Yellow lemon & 0.421 & 0.454 & 251.3 \\
\hline Orange & 0.515 & 0.402 & 140.0 \\
\hline Pink rose & 0.381 & 0.318 & 153.7 \\
\hline Brown chestnut & 0.427 & 0.351 & 28.0 \\
\hline Red tomato & 0.553 & 0.333 & 31.0 \\
\hline
\end{tabular}

\begin{tabular}{|l|c|c|c|}
\cline { 2 - 4 } \multicolumn{1}{c|}{} & $\mathbf{x}$ & $\mathbf{y}$ & $\mathbf{Y}\left(\mathrm{cd} / \mathrm{m}^{2}\right)$ \\
\hline Purple aubergine & 0.516 & 0.348 & 8.3 \\
\hline Green water-melon & 0.400 & 0.475 & 8.1 \\
\hline Green lettuce & 0.470 & 0.471 & 53.0 \\
\hline Yellow lemon & 0.483 & 0.416 & 150.7 \\
\hline Orange & 0.591 & 0.388 & 97.0 \\
\hline Pink rose & 0.531 & 0.368 & 92.0 \\
\hline Brown chestnut & 0.562 & 0.365 & 8.0 \\
\hline Red tomato & 0.635 & 0.330 & 28.0 \\
\hline
\end{tabular}



Table III: 1931 CIE (x,y) chromaticity coordinates, SVF coordinates $\left(\mathrm{V}_{\mathrm{y}}, \mathrm{F}_{1}, \mathrm{~F}_{2}\right)$, Chroma $\mathrm{C}$ and hue-angle $\mathrm{h}$, for the remembered average color for PHY students and ARTS students, repectively. a) Illuminant $\mathrm{D}_{65}$; b) illuminant $\mathrm{A}$.

\begin{tabular}{|c|c|c|c|c|c|c|c|c|c|c|c|c|c|c|}
\hline \multirow[t]{2}{*}{ a) } & \multicolumn{7}{|c|}{ PHY } & \multicolumn{7}{|c|}{ ARTS } \\
\hline & $\mathbf{x}$ & $\mathbf{y}$ & $\mathbf{V}_{\mathbf{y}}$ & $\mathbf{F}_{1}$ & $\mathbf{F}_{2}$ & $\mathbf{C}$ & $\mathbf{h}$ & $\mathbf{x}$ & $\mathbf{y}$ & $\mathbf{V}_{\mathbf{y}}$ & $\mathbf{F}_{1}$ & $\mathbf{F}_{2}$ & $\mathbf{C}$ & $\mathbf{h}$ \\
\hline Purple aubergine & 0.360 & 0.273 & 5.47 & 8.02 & -2.03 & 8.27 & -14.20 & 0.347 & 0.268 & 5.43 & 7.50 & -2.73 & 7.98 & -20.00 \\
\hline Green water-melon & 0.294 & 0.409 & 5.82 & -5.35 & 2.37 & 5.85 & 156.11 & 0.294 & 0.406 & 5.73 & -5.16 & 2.26 & 5.63 & 156.35 \\
\hline Green lettuce & 0.369 & 0.487 & 11.40 & -7.77 & 11.29 & 13.71 & 124.54 & 0.367 & 0.483 & 11.53 & -7.69 & 11.14 & 13.54 & 124.62 \\
\hline Yellow lemon & 0.434 & 0.471 & 14.27 & -3.08 & 16.49 & 16.78 & 100.58 & 0.430 & 0.466 & 14.30 & -2.87 & 15.86 & 16.12 & 100.26 \\
\hline Orange & 0.536 & 0.398 & 11.37 & 11.69 & 15.00 & 19.02 & 52.07 & 0.533 & 0.396 & 11.26 & 11.78 & 14.48 & 18.67 & 50.87 \\
\hline Pink rose & 0.382 & 0.313 & 12.48 & 10.37 & 1.10 & 10.43 & 6.06 & 0.379 & 0.317 & 12.74 & 9.62 & 1.34 & 9.71 & 7.93 \\
\hline Brown chestnut & 0.410 & 0.358 & 5.83 & 4.77 & 3.08 & 5.68 & 32.85 & 0.399 & 0.360 & 5.81 & 3.94 & 2.90 & 4.89 & 36.35 \\
\hline Red tomato & 0.560 & 0.320 & 7.63 & 19.94 & 6.81 & 21.07 & 18.86 & 0.552 & 0.331 & 8.07 & 18.86 & 7.54 & 20.31 & 21.79 \\
\hline
\end{tabular}

\begin{tabular}{|c|c|c|c|c|c|c|c|c|c|c|c|c|c|c|}
\hline \multirow[t]{2}{*}{ b) } & \multicolumn{7}{|c|}{ PHY } & \multicolumn{7}{|c|}{ ARTS } \\
\hline & $\mathbf{x}$ & $\mathbf{y}$ & $\mathbf{V}_{\mathbf{y}}$ & $\mathbf{F}_{1}$ & $\mathbf{F}_{2}$ & $\mathbf{C}$ & $\mathbf{h}$ & $\mathbf{x}$ & $\mathbf{y}$ & $\mathbf{V}_{\mathbf{y}}$ & $\mathbf{F}_{1}$ & $\mathbf{F}_{2}$ & $\mathbf{C}$ & h \\
\hline Purple aubergine & 0.524 & 0.338 & 4.40 & 7.98 & -1.43 & 8.11 & -10.16 & 0.526 & 0.333 & 4.50 & 8.30 & -1.43 & 8.42 & -9.78 \\
\hline Green water-melon & 0.403 & 0.467 & 4.34 & -4.46 & 1.21 & 4.62 & 164.82 & 0.403 & 0.465 & 4.32 & -4.32 & 1.13 & 4.47 & 165.34 \\
\hline Green lettuce & 0.463 & 0.482 & 9.10 & -7.47 & 8.76 & 11.51 & 130.46 & 0.466 & 0.477 & 9.05 & -6.87 & 8.40 & 10.85 & 52.25 \\
\hline Yellow lemon & 0.484 & 0.414 & 11.63 & 1.04 & 3.66 & 3.80 & 74.14 & 0.484 & 0.414 & 11.62 & 1.01 & 3.71 & 3.85 & 46.06 \\
\hline Orange & 0.596 & 0.383 & 10.08 & 7.15 & 13.82 & 15.56 & 62.64 & 0.593 & 0.385 & 10.02 & 6.77 & 13.59 & 15.18 & 48.16 \\
\hline Pink rose & 0.527 & 0.365 & 10.68 & 9.82 & 1.86 & 9.99 & 10.73 & 0.525 & 0.368 & 10.79 & 9.30 & 1.97 & 9.51 & 78.30 \\
\hline Brown chestnut & 0.542 & 0.386 & 4.53 & 3.91 & 3.01 & 4.93 & 37.59 & 0.533 & 0.389 & 4.25 & 3.28 & 2.58 & 4.17 & 52.25 \\
\hline Red tomato & 0.654 & 0.32 & 6.68 & 15.82 & 7.93 & 17.70 & 26.62 & 0.646 & 0.327 & 6.94 & 14.91 & 8.32 & 17.07 & 64.02 \\
\hline
\end{tabular}


Table IV: Dominant wavelengths and colorimetric purity of each of the familiar objects with both illuminants; colorimetric purities of the remembered colors for both populations and illuminants.

\begin{tabular}{|l|c|c|c|c|c|c|c|c|}
\cline { 2 - 10 } \multicolumn{2}{c|}{} & \multicolumn{4}{c}{ illuminant $\mathrm{D}_{65}$} & \multicolumn{4}{c|}{ illuminant A } \\
\cline { 2 - 10 } & $\lambda_{\mathbf{d}}$ & $\mathbf{P}_{\mathbf{c}}$ & $\mathbf{P}_{\mathbf{c}}$ (PHY) & $\mathbf{P}_{\mathbf{c}}$ (ARTS) & $\lambda_{\mathbf{d}}$ & $\mathbf{P}_{\mathbf{c}}$ & $\mathbf{P}_{\mathbf{c}}$ (PHY) & $\mathbf{P}_{\mathbf{c}}$ (ARTS) \\
\hline Purple aubergine & $513^{*}$ & 0.18 & 0.17 & 0.15 & $522^{*}$ & 0.22 & 0.26 & 0.28 \\
\hline Green water-melon & 538 & 0.36 & 0.34 & 0.33 & 525 & 0.29 & 0.26 & 0.25 \\
\hline Green lettuce & 570 & 0.68 & 0.73 & 0.72 & 575 & 0.65 & 0.68 & 0.66 \\
\hline Yellow lemon & 575 & 0.75 & 0.82 & 0.80 & 590 & 0.31 & 0.30 & 0.30 \\
\hline Orange & 589 & 0.81 & 0.85 & 0.84 & 596 & 0.85 & 0.85 & 0.84 \\
\hline Pink rose & $495^{*}$ & 0.14 & 0.15 & 0.14 & $506^{*}$ & 0.22 & 0.21 & 0.20 \\
\hline Brown chestnut & 598 & 0.42 & 0.41 & 0.39 & 615 & 0.43 & 0.47 & 0.43 \\
\hline Red tomato & 609 & 0.69 & 0.67 & 0.68 & 620 & 0.70 & 0.77 & 0.77 \\
\hline
\end{tabular}

* Complementary wavelenght 
Table V: Variation of mean SVF lightness difference, $\Delta \mathbf{V}_{\mathbf{y}}$, SVF chroma difference, $\Delta \mathbf{C}$, SVF hue-angle difference, $\Delta \mathbf{h}, \mathrm{SVF}$ color difference, $\Delta \mathrm{E}$, and normalized SVF color difference, $\Delta \mathrm{En}$. PHY population. a) Illuminant $\mathrm{D}_{65} ;$ b) illuminant $A$.

\begin{tabular}{|l|c|c|c|c|c|}
\cline { 2 - 6 } \multicolumn{1}{c|}{} & $\Delta \mathbf{V}_{\mathbf{y}}$ & $\Delta \mathbf{C}$ & $\Delta \mathbf{h}$ & $\Delta \mathbf{E}$ & $\Delta \mathrm{En}$ \\
\hline Purple aubergine & 1.45 & 1.31 & 0.19 & 4.04 & 1.31 \\
\hline Green water-melon & 0.00 & -0.12 & 1.23 & 1.25 & 1.47 \\
\hline Green lettuce & 1.13 & 3.41 & 9.66 & 5.14 & 1.33 \\
\hline Yellow lemon & 0.46 & 3.16 & 2.49 & 4.15 & 2.01 \\
\hline Orange & 0.13 & 2.21 & -0.83 & 3.37 & 2.39 \\
\hline Pink rose & 0.85 & 0.86 & -2.66 & 4.19 & 1.79 \\
\hline Brown chestnut & -0.01 & -1.34 & 7.95 & 2.97 & 3.81 \\
\hline Red tomato & 1.52 & 4.50 & -2.69 & 6.13 & 1.38 \\
\hline
\end{tabular}

\begin{tabular}{|l|c|c|c|c|c|}
\cline { 2 - 5 } \multicolumn{1}{c|}{ b) } & $\mathbf{\Delta} \mathbf{V}_{\mathbf{y}}$ & $\boldsymbol{\Delta} \mathbf{C}$ & $\mathbf{\Delta}$ & $\boldsymbol{\Delta} \mathbf{E}$ & $\Delta \mathbf{E n}$ \\
\hline Purple aubergine & 1.09 & 3.07 & -3.70 & 4.17 & 1.35 \\
\hline Green water-melon & 1.07 & 0.58 & 1.78 & 2.64 & 1.36 \\
\hline Green lettuce & 1.42 & 2.65 & 2.70 & 4.83 & 1.65 \\
\hline Yellow lemon & 0.08 & -0.04 & -4.88 & 0.42 & 2.47 \\
\hline Orange & 0.29 & 0.86 & -2.42 & 2.59 & 1.80 \\
\hline Pink rose & 1.09 & 0.74 & -2.67 & 4.02 & 2.06 \\
\hline Brown chestnut & 1.28 & -0.07 & 15.38 & 3.81 & 1.69 \\
\hline Red tomato & 0.84 & 3.47 & 1.64 & 4.43 & 1.34 \\
\hline
\end{tabular}


Table VI: As Table V but for ARTS population. a) Illuminant $D_{65}$; b) illuminant $A$.

\begin{tabular}{|l|c|c|c|c|c|}
\cline { 2 - 6 } \multicolumn{1}{c|}{ a) } & $\boldsymbol{\Delta} \mathbf{V}_{\mathbf{y}}$ & $\boldsymbol{\Delta} \mathbf{C}$ & $\mathbf{\Delta}$ & $\Delta \mathbf{E}$ & $\Delta \mathbf{E n}$ \\
\hline Purple aubergine & 1.41 & 1.01 & -5.37 & 3.86 & 1.25 \\
\hline Green water-melon & -0.09 & -0.34 & 1.43 & 1.07 & 1.26 \\
\hline Green lettuce & 1.26 & 3.24 & 9.74 & 5.35 & 1.38 \\
\hline Yellow lemon & 0.49 & 2.52 & 1.97 & 3.91 & 1.90 \\
\hline Orange & 0.02 & 1.85 & -1.88 & 3.25 & 2.30 \\
\hline Pink rose & 1.11 & 0.15 & 0.54 & 4.63 & 1.98 \\
\hline Brown chestnut & -0.03 & -2.12 & 10.95 & 3.43 & 4.40 \\
\hline Red tomato & 1.96 & 3.76 & 0.19 & 6.17 & 1.39 \\
\hline
\end{tabular}

\begin{tabular}{|l|c|c|c|c|c|}
\cline { 2 - 6 } \multicolumn{1}{c|}{ b) } & $\boldsymbol{\Delta} \mathbf{V}_{\mathbf{y}}$ & $\boldsymbol{\Delta} \mathbf{C}$ & $\boldsymbol{\Delta} \mathbf{h}$ & $\mathbf{\Delta} \mathbf{E}$ & $\Delta \mathbf{E n}$ \\
\hline Purple aubergine & 1.19 & 3.39 & -3.61 & 4.57 & 1.47 \\
\hline Green water-melon & 1.05 & 0.42 & 2.21 & 2.55 & 1.31 \\
\hline Green lettuce & 1.37 & 1.99 & 1.38 & 4.60 & 1.60 \\
\hline Yellow lemon & 0.07 & 0.00 & -4.35 & 0.38 & 2.24 \\
\hline Orange & 0.23 & 0.45 & -1.42 & 2.37 & 1.65 \\
\hline Pink rose & 1.20 & 0.25 & -1.34 & 4.10 & 2.10 \\
\hline Brown chestnut & 1.00 & -0.84 & 15.30 & 3.13 & 1.39 \\
\hline Red tomato & 1.10 & 2.87 & 4.16 & 4.42 & 1.34 \\
\hline
\end{tabular}


Table VII: Relation of t-statistic values and significant coefficients, $\alpha$, for both populations. PHY and ARTS students, and illuminants $D_{65}$ and $A$.

\begin{tabular}{|l|c|c|c|c|c|c|c|c|}
\cline { 2 - 9 } \multicolumn{1}{c|}{} & \multicolumn{4}{c|}{ Physics/Arts } & \multicolumn{2}{c|}{ Physics } & \multicolumn{2}{c|}{ Arts } \\
\cline { 2 - 9 } & $\begin{array}{c}\text { Illuminant } \\
D_{65}\end{array}$ & \multicolumn{2}{|c|}{ Illuminant A } & \multicolumn{3}{|c|}{ Illuminant $\mathrm{D}_{65} /$ illuminant A } \\
\cline { 2 - 9 } & t-stat & $\alpha$ & t-stat & $\alpha$ & t-stat & $\alpha$ & t-stat & $\alpha$ \\
\hline Purple aubergine & 0.82 & 0.41 & -1.39 & 0.17 & -0.51 & 0.61 & -2.84 & 0.01 \\
\hline $\begin{array}{l}\text { Green water- } \\
\text { melon }\end{array}$ & 1.13 & 0.26 & 0.37 & 0.71 & -5.90 & 0.00 & -7.72 & 0.00 \\
\hline Green lettuce & -0.68 & 0.50 & 0.85 & 0.40 & 1.06 & 0.29 & 2.68 & 0.01 \\
\hline Yellow lemon & 0.75 & 0.46 & 1.43 & 0.16 & 15.76 & 0.00 & 15.53 & 0.00 \\
\hline Orange & 0.52 & 0.60 & 1.37 & 0.17 & 3.77 & 0.00 & 4.61 & 0.00 \\
\hline Pink rose & -1.24 & 0.22 & -0.24 & 0.81 & 0.56 & 0.58 & 1.53 & 0.13 \\
\hline Brown chestnut & -2.00 & 0.05 & 2.50 & 0.01 & -3.10 & 0.00 & 1.29 & 0.20 \\
\hline Red tomato & -0.16 & 0.87 & 0.05 & 0.96 & 8.29 & 0.00 & 6.69 & 0.00 \\
\hline
\end{tabular}

